\title{
Methodological approach to microscopic colitis diagnosis: reply
}

\author{
Raul S. Gonzalez ${ }^{1}$ (1)
}

Received: 14 January 2020 / Revised: 14 January 2020 / Accepted: 16 January 2020 / Published online: 24 January 2020

(C) Springer-Verlag GmbH Germany, part of Springer Nature 2020

We appreciate the thoughtful response by Villanacci et al. to our manuscript. We agree that proper specimen procurement (by gastroenterologists) and orientation (by histotechnicians) is vital to the accurate diagnosis of microscopic colitis, as it is to many diagnoses. (This has been formally evaluated in the context of assessing for histologic gastric atrophy [1].)

We can fortunately report that in our experience, gastroenterologists tend to sample both the right and left colon, as they recommend. For the second point, however, optimum embedding is not always achieved, particularly in busy (and potentially understaffed) laboratories. Our retrospective analysis did not account for sampling adequacy or quality of biopsy embedding, preferring to focus on using actual, previously handled cases from our archives. For real-time cases where features diagnostic of microscopic colitis appear equivocal, pathologists cannot of course request additional tissue from the gastroenterologist, but they can consider the possibility of re-embedding the biopsy tissue, or perhaps cutting additional levels in the hopes of obtaining a more clear picture of the overall changes present within the specimen.

\section{Reference}

1. Cotruta B, Gheorghe C, Iacob R, Dumbrava M, Radu C, Bancila I, Becheanu G (2017) The orientation of gastric biopsy samples improves the inter-observer agreement of the OLGA staging system. J Gastrointestin Liver Dis 26:351-356

Publisher's note Springer Nature remains neutral with regard to jurisdictional claims in published maps and institutional affiliations.

See related article: https://doi.org/10.1007/s00428-020-02754-3

Raul S. Gonzalez

rgonzal5@bidmc.harvard.edu

1 Department of Pathology, Beth Israel Deaconess Medical Center, Boston, MA, USA 